University of Louisville

ThinkIR: The University of Louisville's Institutional Repository

$12-2013$

\title{
Mutant drought phenotype investigation : a look into effects of protein prenylation on water utilization in conditions of varying soil saturation and gene knockout.
}

Casey Rasmussen

University of Louisville

Follow this and additional works at: https://ir.library.louisville.edu/honors

Part of the Biology Commons

\section{Recommended Citation}

Rasmussen, Casey, "Mutant drought phenotype investigation : a look into effects of protein prenylation on water utilization in conditions of varying soil saturation and gene knockout." (2013). College of Arts \& Sciences Senior Honors Theses. Paper 95.

http://doi.org/10.18297/honors/95

This Senior Honors Thesis is brought to you for free and open access by the College of Arts \& Sciences at ThinkIR: The University of Louisville's Institutional Repository. It has been accepted for inclusion in College of Arts \& Sciences Senior Honors Theses by an authorized administrator of ThinkIR: The University of Louisville's Institutional Repository. This title appears here courtesy of the author, who has retained all other copyrights. For more information, please contact thinkir@louisville.edu. 


\section{MUTANT DROUGHT PHENOTYPE INVESTIGATION}

A Look Into the Effects of Protein Prenylation on Water Utilization in Conditions of Varying Soil Saturation and Gene Knockout

\section{By}

Casey Rasmussen

Submitted in partial fulfillment of the requirements

for Graduation magna cum laude

University of Louisville

December, 2013 


\section{$\underline{\text { Abstract }}$}

Plants respond to environmental stress, such as drought, with increases in levels of Abscisic Acid (ABA). This stress response allows greater survival rates but results in the plants producing lower seed yield and biomass. Certain mutant strains of the Arabidopsis plant have been identified with mutations in coding regions involved in the formation of the $\alpha$ and $\beta$ subunits of PFT and PGGT-I genes involved in protein prenylation. We explored the possibility of these mutant strains to better preserve seed yield and plant biomass under drought stressing conditions in comparison to the wild type (Columbia) strain, based on the mutants' hypersensitivity to ABA. Our data did not support the hypothesis that these mutant strains offer better preservation in these categories, and the functioning of the PFT and PGGT-I genes may be different than originally proposed. 
Mutant Drought Phenotype Investigation 3

\section{Introduction}

Enormous economical damage is incurred each year as a result of crop yield loss. This is due primarily to abiotic stress, which can reduce major crop yields by as much as 50\% (Boyer, 1982). With this issue at hand, there is an increasing opportunity for the utilization of science to help. If a genetically modified drought tolerant crop were to be produced, the incurrences of these losses due to uncontrollable drought conditions could be minimized, if not eliminated. Due to the potential for dramatic positive scientific improvements in this area of agriculture, a large amount of research is being performed to examine the possibility of creating drought resistant crop lines through the use of transgenic methods (Gamboa, Baltierra, Leon, \& Krauskopf, 2013; Ghabooli et al., 2013; Kumar, Uzma, Khan, Abbas, \& Ali, 2013; Ubaidillah et al., 2013).

Abscisic acid (ABA) is a chemical signal of stress produced in plants. The increase in ABA in plants can occur as a result of drought stress or high salinity conditions (Gamboa et al., 2013; Running et al., 2004). ABA causes a myriad of responses to enhance survivability to stress conditions, including reducing water loss via closure of stomata (the leaf openings that let in carbon dioxide). Mutant lines of certain plant species have been identified that present ABA hypersensitivity, and demonstrate diminished seed yield and enhanced stomatal closure (Cutler, Ghassemian, Bonetta, Cooney, \& McCourt, 1996; Pei, Ghassemian, Kwak, McCourt, \& Schroeder, 1998; Running et al., 2004).

The species being used in our research is Arabidopsis thaliana. There are many reasons for the use of this species of plant. The Arabidopsis plant is small, grows relatively rapidly, possesses a small genome, has a high seed yield of offspring, and is relatively easy to insert foreign DNA into, as well as mutate DNA.

Farnesol is essentially a lipid found in Eukaryotes. This lipid, farnesol, can then undergo two steps of phosphorylation, creating the phosphorylated lipid farnesyl monophosphate (FP) after the first phosphorylation and farnesyl diphosphate (FPP) following the second phosphorylation (Fitzpatrick, Bhandari, \& Crowell, 2011; Hemmerlin \& Bach, 2000; Hemmerlin et al., 2006). The enzyme used to mediate the second step of this phosphorylation process is still unknown. The FOLK gene was recently found to code for the enzyme, farnesyl kinase, used to mediate the phosphorelation of farnesyl to farnesyl monophosphate but not farnesyl monophosphate to farnesyl diphosphate (Fitzpatrick et al., 2011). After the conversion of FP to FPP, the fate of the farnesyl diphosphate is then protein prenylation, to attach the diphosphate lipid to a protein using the enzyme protein farnesyltransferase (PFT) (Crowell \& Huizinga, 2009; Zhang \& Casey, 1996).

The pluripetala (plp) mutant plants lack the DNA sequence that encodes the $\alpha$-subunit shared by protein farnesyltransferase (PFT) and protein gernylgeranyltransferase (PGGT) involved in protein prenylation (Running et al., 2004). Protein prenylation is a conserved function in fungi, plants, and animals (Maurer-Stroh, Washietl, \& Eisenhaber, 2003; Yalovsky, Rodr Guez-Concepcion, \& Gruissem, 1999). ABA hypersensitivity has been demonstrated in the era1 mutant Arabidopsis plants, which present a disruption of the encoding and correct 
formation of the PFT $\beta$-subunit (Cutler et al., 1996; Running et al., 2004). Due to the nature of the $\alpha$-subunit being involved in the activity of both PFT and PGGT, it has been hypothesized the plp mutants should exhibit even more severe ABA hypersensivity than the era1 mutants (Running et al., 2004). Indeed, plp mutants do show hypersensitivity to ABA in inhibition of seed germination (Running et al., 2004); however, this sensitivity is not as severe as in era1.

Recently the Running laboratory also identified a gene that encodes a protein that is similar to PLP in sequence (Qin Zeng and Mark P. Running, unpublished). This gene, termed PROTEIN PRENYLTRANSFERASE ALPHA SUBUNIT-LIKE, (PPAL), also shows slight hypersensitivity to ABA in seed germination assays when mutated, raising the possibility that the ppal mutant might, like era1, also be sensitive to ABAinduced drought responses.

\section{Specific Aims}

The specific aims of this experiment will be to test the transpiration rates of Arabidopsis plp and ppal plants under water stressing conditions, and measure the seed yield and biomass resulting from water stressed plants compared to wellwatered controls. Our hypotheses are 1) the ABA hypersensitivity of plp and ppal mutants will lead to lower transpiration rates under drought conditions, and 2) treatment with varying types of drought stress will lead to preservation of seed yield and biomass compared to wild type.

The first portion of this experiment involves measuring the transpiration of the plants. This will be done to observe the rate at which the plants respond to the ABA hypersensitivity, and consequently how quickly the guard cells begin to close and transpiration decreases during water-stressed conditions.

The second portion of this experiment will involve the phenotypic observation and growth parameters of Arabidopsis plants under three different water-stressing conditions. The aim is to determine whether seed yield and biomass can be preserved more readily under drought stress in plp and ppal mutants.

\section{Hypothesis}

For the first portion of this experiment, it is anticipated that the mutant plants will exhibit ABA sensitivity in the form of decreased transpiration rates as soil water saturation decreases. It is believed that as the concentration of ABA increases under the increased stress of lower water saturation, guard cells will close more, resulting in lower observed transpiration rates. Our hypothesis for this portion is that the plp and ppal mutants will exhibit a higher ABA hypersensitivity, resulting in a faster decrease of transpiration rates than the wild type control group.

For the second experiment, it is our hypothesis that only the plp mutants will exhibit developmental changes under the water-stressing condition. We believe the wild type plants will still exhibit normal developmental qualities, while the $p l p$ plants will exhibit an increased amount of carpels, partial formation of stamens to 
Mutant Drought Phenotype Investigation 5

carpels, and potentially other developmental abnormalities at the $30 \%$ saturation condition.

\section{Methods}

The experiment commenced with the weighing of both the dry and $100 \%$ water saturated weights of the pots. The pots were first filled to the very top with dry soil and weighed. The weights were recorded as the "dry weight" of each pot and the unwatered soil it contained. The pots were then soaked in water over night, allowing them to reach full water saturation. The pots were again weighed, and the weights were recorded. The difference between these two weights would allow for the calculation of water weight in each pot, and subsequently calculate the weight each pot should be at 30\%, 70\%, and 100\% water saturation. The plp mutant Arabidopsis was planted first. This mutant line of Arabidopsis was planted first due to the increased amount of time required to germinate in relation to the wild type (Columbia) and ppal mutant strains. Approximately nine seeds of $p l p$ mutant Arabidopsis were planted in each pot. Nine seeds were planted for this particular strain instead of the six for the other two strains due to lower successful germination rates, comparatively. Each tray of plants contained 18 pots, and three trays were planted. Three trays were used so each could be manipulated with a separate condition of 30\%, 70\% and 100\% water saturation. After the seeds were planted, the tray was filled approximately one third of the way with standing water, covered with a plastic dome, and placed in a cold room for five days to accelerate germination. The same preparation procedure was performed for the ppal and wild type (Columbia) Arabidopsis plants, with the only difference being six seeds were planted in each pot instead of nine. After five days in the cold room at 4 degrees $C$, the plants were moved into the growth chamber under florescent lighting at 21 degrees $C$. The plants continued to receive sufficient water, with a small amount of standing water always being present on the bottom of the trays to encourage healthy germination. The plastic domes remained on the trays, but were pushed back slightly to allow for ventilation and reduce any greenhouse effect from taking place (see image 13). The plastic domes were left on in this manor until the Arabidopsis plants germinated to approximately one to two centimeters in height (see image 14). At this point, the plastic domes were removed, but watering remained unaltered. After roughly one week of inhibited growth of the ppal and wild type (Columbia) strains, and two and a half weeks for the $p l p$ strain, excess water was drained from the trays that would undergo the $30 \%$ and $70 \%$ saturation conditions, and watering was ceased until the pots achieved the corresponding calculated saturation weights. During this time the plants were also moved from the growth chamber to another laboratory room with nearly identical growth racks and lighting (see image 1,2, and 3). The reason for the move was to isolate all trays involved in this experiment to a single location and growth rack, as well as making room for additional newly germinating plants involved in separate studies in the growth chamber. As the experimental pot weights were achieved, water was added on a day-to-day basis until all three trays of pots reached the desired experimental 
water saturation level weights. The experimental data collection commenced on July 22, 2013, and continued through August 1, 2013. Each day at approximately 10 a.m. the nine trays of plants would be gathered and transported to the main laboratory. Starting with $30 \%$ plp, each individual pot would be weighed, the weight would be recorded, and additional water would be added via a micropipette to bring the weight of the pot back up to the corresponding calculated weight for the experimental $30 \%$ saturation condition. The same procedure would then take place for the $70 \%$ and $100 \%$ saturation plp plants, followed by the $30 \%, 70 \%$, and $100 \%$ ppal plants, and lastly the $30 \%, 70 \%$ and $100 \%$ wild type (Columbia). The plants were weighed and watered in this order for the duration of the experiment and data collection. Since a micropipette was utilized to water the plants, most were watered to the desired saturation level within a range of $\pm 0.1 \mathrm{~g}$. If errors greater than this were observed, efforts would be made to correct for the error by accounting for the magnitude of the excess over the course of the next few pots. For example, if one pot were watered to $0.9 \mathrm{~g}$ over what was experimentally calculated to be the desired saturation weight, the next three pots would be watered to $0.3 \mathrm{~g}$ below their corresponding calculated experimental saturation weight. These occurrences were minimal. A Symmetry Cole-Parmer ED2000 scale with $d=0.1 \mathrm{~g}$ was used for the dry weights, saturated weights, and day-to-day experimental weighing during this period of time. As of August 1, 2013, the vast majority of the $100 \%$ saturation condition of the wild type (Columbia) appeared to be dead, and the watering and weighing portion of the experiment ceased. The plants were moved back to the growth racks in the support laboratory, and remained under florescent lighting without watering for approximately six weeks (see image 14). This was to allow for all water weight to be removed from the soil and plants so biomass weights could be attained. After the six-week time period, the plants were stripped of the seeds and siliques. This was performed in six pot-pooled installments. The amount of plants in each pot was also recorded for water utilization per plant, per plant seed yield, and average biomass per plant calculations. The silique and seed weights were recorded to assess the seed yield of the different strains and under the different water saturation conditions. With eighteen pots per tray, and six pot increments, three data points per strain and condition would be gathered. After the seed and siliques were stripped from the plants and weighed, the plants were harvested and weighed for biomass data. The plants were weighed in pools of six pots, the same as the seed yields. The plants were cut near the base, allowing for the stalk to be taken separate from the leaves and roots. The stalks were then cut into smaller portions to fit on weighing boats. The leaves and rooting was then gathered with the use of laboratory needle-nose tweezers. As the plants were uprooted from the soil, a second pair of needle-nosed tweezers was used to strip the rooting of any attached soil. The stalk base, leaves, and roots were then added to the weighing boat already containing the fragmented stalks. These weights were then recorded for each strain and saturation condition. The seed yield weights and plant biomass weight were taken on a Citizen model CY 204 scale with a d=0.1mg. The seeds were placed in small envelopes and labeled; potentially to be used in future experiments. The plants' remains were disposed of in biohazard waste containers. 
Mutant Drought Phenotype Investigation 7

\section{$\underline{\text { Results }}$}

One of the primary interests of this experiment was the water utilization of the three different strains of Arabidopsis: plp, ppal, and wild type (Columbia); under the three different water saturation conditions: 30\%, 70\%, and 100\%. The water utilization was calculated indirectly by the daily weights of the plants. At the beginning of the experiment, during the planting stages, the pots were all weighed with dry soil. The pots were then soaked to full saturation, giving the $100 \%$ saturation weight of each pot. Water weight could then be calculated by taking the $(100 \%$ saturation weight - initial pot dry weight $)=$ water weight of each pot. The $30 \%$ saturation weight and $70 \%$ saturation weight were then calculated by ((water weight $\times 0.30)+$ initial pot dry weight $)=30 \%$ saturation weight, and ((water weight $x 0.70)+$ initial pot dry weight $)=70 \%$ saturation. Since the pots were all watered to $\pm 0.1 \mathrm{~g}$ or the desired saturation, and any errors were accounted for, it can be assumed that the daily water utilization would be (calculated condition weight daily weight) $=$ water used. For the purposes of this experiment, the average of the daily use per plant for each strain and saturation condition were the values of interest. The following were the results in grams of water used per plant per day: $30 \%$ Columbia $=3.09,70 \%$ Columbia $=2.16,100 \%$ Columbia $=1.63,30 \%$ plp $=5.35$, $70 \%$ plp $=3.76,100 \%$ plp $=3.45,30 \%$ ppal $=4.63,70 \%$ ppal $=1.57,100 \% \mathrm{ppal}=$ 1.53 (see figure 1 and 2). There appears to be a trend of increased water utilization inversely proportional to water saturation. Any pots that failed to successfully germinate viable Arabidopsis plants were excluded from the averaging calculations. Additionally, two Columbia pots, one plp pot, and three ppal pots had no Arabidopsis germination, and the average rate of evaporation in these empty pots was calculated to be 16.6 grams/day, 16.4grams/day, and 12.5 grams/day respectively. Plants per pots were also measured, and an average plants per pot for each condition and strain was also calculated. The results in plants per pot were: 30\% Columbia $=$ 5.944, 70\% Columbia $=5.722,100 \%$ Columbia $=5.750,30 \%$ plp $=3.667,70 \%$ plp $=$ $3.500,100 \% \mathrm{plp}=3.353,30 \% \mathrm{ppal}=4.667,70 \% \mathrm{ppal}=6.389,100 \% \mathrm{ppal}=6.056$ (see figure 1). The average amount of successful plant germination per pot within each strain is relatively constant, with the exception of the $30 \% \mathrm{ppal}$ condition as opposed to the $70 \%$ ppal and $100 \%$ ppal.

Average seed yield was gathered as a measure of taking the weight of collected seed yield of each of the six pot increments divided by the amount of plant germination in the corresponding six pots. The average for each experimental condition for each of the three strains was then calculated by taking the average of the three averages of the 18 pots corresponding to each tray, broken into the 6 pot increments. The results in grams per plant were: 30\% Columbia $=0.02305,70 \%$ Columbia $=0.03071,100 \%$ Columbia $=0.02695,30 \%$ plp $=0.01668,70 \%$ plp $=$ $0.02125,100 \% \mathrm{plp}=0.01856,30 \% \mathrm{ppal}=0.006341,70 \% \mathrm{ppal}=0.008509,100 \%$ ppal $=0.009148$ (see figure 1 and 3). Average plant biomasses were calculated in the same manner, by taking the total weight of the six pot pool, divided by the amount of plants corresponding to those six pots, then taking the average of the three corresponding six pot pools for each tray. The results for the average plant 
biomasses in grams per plant were: $30 \%$ Columbia $=0.04214,70 \%$ Columbia $=$ $0.04787,100 \%$ Columbia $=0.04389,30 \%$ plp $=0.04364,70 \%$ plp $=0.05936,100 \%$ $p l p=0.03335,30 \%$ ppal $=0.03965,70 \%$ ppal $=0.04616,100 \% p p a l=0.06147$ (See figure 1 and 4 ).

\section{$\underline{\text { Discussion }}$}

The first aspect of our original hypothesis was that the previously observed ABA hypersensitivity of the plp and ppal mutants (Running et al, 2004; Qin Zeng and Mark P. Running, unpublished) would lead to lower transpiration rates under drought conditions as opposed to the wild type (Columbia) strain. Of the data collected, this hypothesis is not supported. In the $30 \%$ saturation conditions, the wild type (Columbia) strain actually shows the lowest level of water utilization per plant per day, of 3.09 grams.

One complication arising with this experiment was the inability to control for evaporation from the soil taking place and resulting in water loss and subsequent decreased weight as opposed to plant transpiration. For this reason, a "corrected" water utilization per plant per day calculation was performed. This calculation was essentially an effort to account for the water loss due to evaporation instead of plant transpiration. The calculation involved using the pots that failed to produce viable offspring as controls for base rate water utilization. The calculation was (((saturation condition weight - daily weight taken) - base rate of evaporation) / number of viable plants in pot). This calculation produced many negative and nearzero values for daily water use per plant. This calculation was minimally useful for the purposes of statistical analysis, but provided valuable insight into potential experimental limitations. First, it is likely that given many of the calculations using this "corrected" formula returned negative values, that the coverings of the plant leaves create a significant buffer to water evaporation from the soil. This creates an issue with determining exactly how much of the calculation of daily water use per plant is truly related to the plants water utilization verses simple water evaporation from the soil.

This led to calculating the average plants per pot per strain per saturation condition to examine any correlations between the average water utilization and the average number of plants as a potential experiment confound. In the $30 \%$ condition, the $p l p$ strain shows the highest water utilization per plant (5.35 g/plant). In addition, $p l p$ also has the lowest average plants per pot (3.667 plants/pot) of the $30 \%$ saturation conditions of the strains. Conversely, the wild type (Columbia), with the lowest average water utilization per plant $(3.09 \mathrm{~g} /$ plant $)$ shows the highest average plants per pot (5.944 plants/pot). Ppal demonstrates intermediate values for both water utilization and plants per pot, demonstrating a trending inversely proportional correlation between plants per pot and average water utilization per plant per day. Due to this finding, it is difficult to conclude if the driving force behind the water utilization is evaporation of the plants themselves; although, due to the inverse correlation between average plants per pot and water utilization, we believe evaporation played a significant role in the increased water utilization data 
gathered in opposition to our original hypothesis in the $30 \%$ saturation condition. Additionally, it is noteworthy that the plp strain plants have increased structural abnormalities in relation to the wild type (Columbia) and ppal strains, of particular note in the leaf formation. The plp strain produces a much more curled and thick leaf, which would likely provide less buffering to evaporation of water from the soil as opposed to the other two strains. This would also support the belief that the water utilization data gathered in the $30 \%$ saturation condition was largely influenced by rates of evaporation.

In the $70 \%$ saturation condition, plp again showed the highest rate of water utilization per plant ( $3.76 \mathrm{~g} / \mathrm{plant}$ ), as well as the lowest average plants per pot (3.500 plants/pot). Also in the 70\% saturation condition, ppal, as opposed to wild type (Columbia) in the $30 \%$ saturation condition, showed the lowest average rate of water utilization per plant (1.57 g/plant); and highly notably also demonstrated the highest average plants per pot (6.389 plants/pot) of the $70 \%$ saturation conditions. This would again be supportive of the believe that leaf covering of the soil played a significant role in the data collected on the rates of water utilization. The $70 \%$ wild type (Columbia) demonstrated intermediate vales in both plants per pot and water utilization per plant, and the same trend observed in the $70 \%$ saturation condition was also present in the $100 \%$ saturation condition, further supporting this belief.

An additional unexpected data finding of the average water utilization calculation is a trend within all strains to increase water utilization as water availability decreases. This is not an intuitively logical finding, and confounding variables may be playing a role. However, it is interesting that this result was observed across all three strains of plants. When examined for a relation to average plants per pot and water utilization within strains between different saturation conditions; wild type (Columbia) appears to show relatively consistent plants per pot across conditions with increasing water utilization with decreasing saturation, plp appears to show the same increasing water utilization with decreasing saturation, but water utilization is also slightly in direct proportion with average plants per pot, while ppal follows the same increasing water utilization with decreasing saturation, it shows a highly inversely proportional relationship between water utilization and average plants per pot. Due to the nature of likely a minimum of three variables present in this set of data: strain, saturation condition, evaporation rate; it is difficult to conclude why this trend is present, although highly interesting. It is possible that certain variables may present more prominently in particular combinations of strains, saturation, and evaporation; and the trend across the three strains with increasing water utilization with decreasing water availability is simply by chance of aligning of the most prominent ratios of these elements. It is also likely additional mechanisms not examined by the data played a significant role in this trend.

The other hypotheses being examined were the potential for the mutant strains of Arabidopsis, plp and ppal, to potentially maintain seed production and growth during water stressed conditions as opposed to wild type (Columbia). The data demonstrates that the average seed yield per plant was highest in the wild type (Columbia), even in comparing the $30 \%$ water saturation condition to the $70 \%$ and $100 \%$ saturation conditions of the mutant strains. In the wild type (Columbia) and 
plp strains, $70 \%$ seed yield was highest with the $100 \%$ and $30 \%$ seed yield being $12 \%-13 \%$, and $22 \%-25 \%$ lower respectively. It may be the case that $70 \%$ water saturation is the plants preferred level of saturation, and $100 \%$ water saturation of the soil impedes optimal plant growth and reproductive efforts; potentially by impeding optimal root formation, by depriving the roots of available oxygen, and by interfering with nutrient absorption. The $30 \%$ condition likely puts the plants in a drought stressing state, and therefore diminishes reproductive efforts, as we expected to observe. The seed yields for the ppal increased directly proportional with water saturation of the soil, but the ppal strain also demonstrated a $25 \%$ decrease in seed yield between the $70 \%$ and $30 \%$ water saturation conditions, indicating neither mutant strain seems to have the ability to offer better protection to seed yields under drought stressed conditions as opposed to wild type (Columbia). Also, the measurements of seed yield are not strictly seeds. They also include some weight as a result of the siliques the seeds are held in. This was believed to have minimal impact on the weight in the case of the wild type (Columbia) and ppal strains, and was likely fairly consistent both within these strains and between them. It is likely that the measurements of seed yield for the plp mutant are comprised of a larger proportion of additional biomass of the plant than the minor amount believed to be contributed by the siliques of the other two strains. This is due to the nature of the plp mutant and its siliques. The wild type (Columbia) and ppal mutants have very long, fragile, and easy to remove siliques filled with seeds. These are easily separated from the stem of the plant simply by rolling ones fingers down the length of the plant and causing the siliques and seeds to fall onto the scale below. With the plp mutant, the siliques are much less fragile and much more difficult to remove. As a result of this, more of the plant itself would usually come off in addition to the seeds, although efforts were made to remove as much of the material not of interest as possible. In addition, the siliques of the plp mutant appear to be much more structurally sound than the fragile wild type (Columbia) and ppal siliques, so it is possible they added comparatively more mass to the data values as well. Even if this is the case, it is likely the measurement error would have occurred at the same rate within the plp strain, and the conclusion that the data fails to support the hypothesis that the mutant strains are capable of better preserving seed yield under water stressed conditions is likely still valid; unless the proportion of biomass present in the seed yield weight is high in comparison to the amount made up by actual seed yield weight, to the point that it dictated the majority of the weight of the calculation. However, if this is the case, the average seed yield weight per plant would likely be so small it would be difficult to confidently compare the percent differences even within the plp strain, seeing as any loss of any amount of seeds during collection could drastically alter the percent different calculation given this sample size.

Of the strains studied, in conflict with our hypothesis, the wild type (Columbia) produced the most consistent biomass between the three saturation conditions. Again, the highest degree of biomass occurs in the $70 \%$ saturation condition for both the wild type (Columbia) and plp strains. This again is likely due to undesirable effects of $100 \%$ soil saturation on root processes and nutrient uptake. Ppal again demonstrates increasing growth directly proportional to 
increasing water availability, as was the case with seed yield for ppal as well. The plp strain shows the highest weight of plant biomass of all strains and conditions in the $70 \%$ plp water saturation condition. This could be due to two factors, or a combination of these factors. The plp mutant is a shorter, slower growing strain of Arabidopsis, although it appears to have a visibly thicker and more structurally sound stalk. All leaf and reproductive apparatus formation is thick and curled, although also appears to be visibly slightly thicker and more structurally sound as well. In addition, the $p l p$ mutants consistently demonstrated the lowest average viable yield of plants per pot, with an average of only 3.500 plants per pot in the $70 \%$ saturation condition. This may have allowed the plants greater ability to grow on the basis of increased space and decreased competition for light, nutrients, and root formation in the soil. It is also believed, since there is an increased likelihood more of the biomass of the plp mutant may have been lost during the collection of the seed yield weight, that there is good reason to believe the $p l p$ mutant does indeed have a larger average biomass as compared to the wild type (Columbia) and ppal strains, even given its significantly shorter stature. This could be accounted for in the curled nature of the reproductive apparatus and leaves; the increased thickness of the stalk, leaves, and reproductive apparatus; and/or the density of the formation of these structures.

\section{Additional Considerations}

As mentioned, the plp strain was planted at a separate time from the wild type (Columbia) and ppal strains. Another student also working in the same laboratory planted the $p l p$ plants. The guidelines for planting them were followed correctly as described, however the original soil weights are slightly different from those of the wild type (Columbia) and ppal strains. The plp pots were all filled to the top with dirt and soaked in the usual method, but the weights are more variable, 34.3 grams plus or minus 3.3 grams. When the wild type (Columbia) and ppal plants were planted, the pots were all filled with dry soil until they weighed $43.0 \mathrm{~g} \pm 0.1 \mathrm{~g}$. As a result, the wild type (Columbia) and ppal strains were exposed, on average, to slightly more water in each condition, seeing as there was more soil with the capacity to be saturated. This is likely an insignificant experimental deviation, especially since the root system of the plants usually appeared to transcend only

approximately the top half of the depth of each pot. There does not appear to be any significant difference in base evaporation rates as a result of this either, with the ppal strain actually showing the largest difference in between strain analysis; however, it is difficult to confidently analyze this relationship with the base rate of evaporation for the $p l p$ line being based solely on one pot.

When the calculations of the average utilization for the $100 \%$ saturation condition of each of the three strains were performed, the first two days of data collection were excluded from the calculation. This was due to the saturation condition of these plants seemingly not being met prior to the commencement of the experimental data collected. The first day of data collection, many of the $100 \%$ condition plants weighed more than the $100 \%$ saturation condition calculation. 
This difference in weight was likely due to a combination of two factors. The first is the increase in weight due to the biomass of the plants, and the capacity of the plants to hold water in addition to the soil capacity. The second is the way in which these plants were prepared to start the experiment. Since these three trays were to be run at $100 \%$ saturation, water was added to the bottom of the tray, the pots were allowed to soak up as much water as they could to reach $100 \%$ saturation, and the excess water was drained from the bottom of the tray. It is possible the combination of a small amount of excess water left after drainage, as well as the increased biomass of the plants included in the weight account for the seemingly higher than $100 \%$ saturation weights of the plants in the first day. Since many of the numbers were higher than the calculated values on the first day, the decision was made to also exclude values from the next day, as the values would likely be lower than what was actually occurring due to starting with more than a $100 \%$ saturation weight. For these reasons, the data was excluded from the $100 \%$ saturation calculation for both of the first two days of data collection across all strains. The last day of data collection for the $100 \%$ saturation condition of the wild type (Columbia) strain was also excluded from the data due to the plants being dead at this point in time. This means nine days were used for determining the average water utilization for the $100 \%$ water saturation conditions of the plp and ppal strains, and eight days for the wild type (Columbia) strain, as opposed to the eleven days used for all other conditions. This is not believed to have impacted the results, other then minor differences as a result of a smaller data size in the averaging calculations.

An additional potential consideration in regards to the difference in preparation of the plp strain verses the wild type (Columbia) and ppal strains is the data collected on the $100 \%$ saturation condition. For the plp condition, it was possible to water the plants to the $100 \%$ saturated calculation throughout the duration of the experiment. For the $100 \%$ saturation condition of the wild type (Columbia) and ppal strains, it was difficult to achieve the full value of the $100 \%$ calculated saturation weight. In some of the pots, water would begin to leak from the bottom as the corresponding value was achieved. It is likely some plants never fully reached the $100 \%$ saturation value, and there was water loss from the bottom of the pots into the trays, which would have then evaporated. Although this likely altered the data attained, it is believed to be a fairly insignificant alteration in comparison to the other confounds already addressed. Also, if this were occurring, the result would have been to artificially inflate the data attained for average water use per plant per day, which would only serve to further support the conclusions derived from that data.

A final consideration involves seed loss. Due to the nature of the fragile siliques of the wild type (Columbia) and ppal strains, it is likely seed yield was lost during the experiment, during the time the plants were unwatered in the support laboratory, and during the transport from the support laboratory to the main laboratory for seed collection and weighing after the drying period. During the experiment, as the plants were constantly moved from the trays to the scale and back, it is likely some seed loss resulted. During the time the plants were unwatered in the support laboratory, it is likely some of the siliques burst open as they dried, resulting in seed yield loss. During the transport back to the main laboratory after 
being dried, the plants were all in a very fragile state, and it is likely loss of seed yield was unavoidable while being carted back to the main laboratory. The last consideration is likely to have had the largest impact on the seed yield of the plants. Plp is not included in this consideration, at least not in comparison due to degree of occurrence, due to the far less fragile nature of the plp mutant siliques. Although this is likely to have occurred, it is believed to have occurred consistently between the six trays addressed, and likely does not effect the conclusions derived from the data.

\section{Additional Observations/Characterizations/Conclusions}

\section{Wild Type (Columbia)}

Columbia was the most rapidly growing of the three strains used in this experiment. It produced a very tall, slender stalk, with long, medium girth leaves at the base. The Columbia strain produced the largest seed yield per plant by measures of weight. The plants also advanced through the life cycle the most rapidly. The $100 \%$ saturation condition of the Columbia strain was the first to die, and dictated the conclusion of the watering portion of the experiment. Additionally, the $100 \%$ saturation condition appeared to present difficulties related to the high water saturation. This included the decreased average seed yield and average plant biomass as opposed to the $70 \%$ saturation condition, and the plants in the $100 \%$ condition presented with great difficulties growing in a vertical fashion. All plants in the $100 \%$ saturation condition began to fall in the horizontal direction, to a near 90-degree angle. This was believed to be due to the impeding of proper rooting formation and support properties brought on by the high degree of $100 \%$ water saturation.

Plp

Plp was the slowest growing of the three strains used in this experiment. Even with the plp plants having been planted prior to wild type (Columbia) and ppal, the $p l p$ mutants showed no signs of dying in any of the saturation conditions when the watering portion of the experiment was terminated. As with the other strains, the $p l p$ mutant demonstrated decreasing growth rate with decreasing water saturation. It may be possible that not only does the $p l p$ strain grow slower than the other strains tested, but it may have an increased ability to stall its growth while under water stressed conditions, although no data gathered during the course of this experiment is available to support that potential notion. The $p l p$ mutants were the most morphologically different from the wild type (Columbia) strain. The plants exhibited diminished stature, increased thickness and curling of features, and decreased average seed yields.

Ppal 
Ppal appeared to be intermediate to plp and wild type (Columbia) in many of the areas examined in this experiment. Ppal demonstrated an intermediate rate of growth, and some of the plants in the $100 \%$ saturation condition appeared to be dying at the time the watering portion of the experiment was concluded. An interesting note with the ppal mutant, the measurements of average seed yield and average plant biomass collected increased with increasing water saturation, and no negative effects of $100 \%$ water saturation appear to be observed with the ppal mutant. We believe it may be the case that the ppal mutant has the capacity to better thrive under fully saturated, and potentially even supersaturated, water conditions; although further experiments would need to be conducted to examine this possibility, and the agricultural usefulness of a mutant with this quality is likely minimal. Like all other strains used in this experiment, the ppal mutant also appeared to accelerate through the life cycle faster with increasing water saturation levels. There was a small amount of nonvertical growth observed in the $100 \%$ saturation condition of the ppal mutant as well, similar to what was observed in the $100 \%$ saturation wild type (Columbia) group; although, to a much less significant degree. The ppal mutant also presents some minor morphological differences in comparison to the wild type (Columbia) strain. The ppal strain shows smaller leaf formation than the Columbia strain. The leaves are also more ridged along the edges, and appear to have a smoother, less porous, and less "haired" surface. The morphological anatomy of the rest of the plants appears to be comparable to the Columbia morphology.

\section{Connections to Prior Research}

With respect to both the water utilization data and biomass data, it is possible the disruption of the $\alpha$-subunit examined in this study does not serve to function in the manner hypothesized; although further experiments with less potentially confounding factors, larger data sets, and additional research are needed to further examine this potential. Additionally, the trending of increased water utilization with decreasing water saturation is highly interesting and warrants further discussion and speculation. When examining the methods used in related experiments, drought-stressing conditions appear to be performed in a more absolute fashion. In another experiment utilizing the Arabidopsis plant, drought stressing conditions were applied to five to six week old plants, and the drought stress consisted of a complete absence of water for 20 days (Gamboa et al., 2013). In another recent experiment using the AVP1 gene of Arapidopsis in sugar cane, the plants were grown normally for a one week period of time, then subjected to a drought stress condition of withholding water for a two week period of time (Kumar et al., 2013). It is possible that the constant influx of water in our experiment failed to allow for the manifestation of the same drought stress response observed in other experiments where water was completely withheld from the plants for a finite period of time. It may be possible that even at the low level of soil saturation, the plants failed to produce ABA levels high enough to cause the enhanced stomatal closure previously observed (Pei et al., 1998). Although unlikely, it is possible there is a certain level of soil saturation lower than $30 \%$ that must be achieved before 
significant drought stress occurs, and an enhanced period of absorption in preparation for this may occur at soil saturations prior to the threshold. This is solely a speculation based on the data observed in this experiment, and further investigation into the possibility is necessary.

\section{Future Research}

In order to confidently make conclusions on the hypotheses tested in this experiment, addition trials are necessary. In these trials, additional measure should be taken to better control against the confounds identified in this experiment. In the future, it would likely be beneficial to have a single plant in a single pot. This would minimize occurrences of competition between plants, and likely increase the accuracy of water utilization data collected. Additionally, if measures could be taken to better control for water loss due to evaporation, this would also increase the accuracy of the water utilization data collected. In the past, methods of wrapping the pots in shrink-wrap have been used as an effort to minimize the influences of evaporation. If this were done, the shrink-wrap should be right to the soil to avoid creating greenhouse effects under the wrapping and raising the temperatures. Also, this would create a substantial barrier to the watering of the plants.

With evaporation likely playing a considerable role, and the difficulty associated with trying to minimize the influence of it, future experiments to assess the influence of it may be appropriate. This would have its own complications as well, but may lead to more accurate data if evaporation rates can be taken into account in the calculations. This could be done by having a control condition with no plants being watered, with a certain percentage of the pot covered by material in a leaf shape. A base rate of evaporation evaluation could then be made based off the area of the pot's soil covered by the fake leaves. The data from these different areas of fake leaf covering could then be plotted, and a line of best fit could then be established. After this, when trials are being performed with actual plants, the leaf area of the real plants could be taken, and a calculation to account for the likely average rate of evaporation taken place from the line of best fit could be performed. It is likely the leaf sizes of the real plants will increase during the course of the experimental data collection, which would create complications with this method as well; however, it is still likely to increase the accuracy of the data in comparison to the conditions and calculations present in this study. Taking the area measurements of the leaves half way through the data collection may be a potential way to attempt to control for this issue.

From a scientific standpoint, further examination into the difference in the ppal mutants to exhibit increased growth and reproductive effort success even in the presence of high soil saturation conditions may be a worthy endeavor. Further examination into this possibility may lead to the discovery of additional phenotypic observations relating to the ppal mutation, which could potentially be useful in future transgenic studies in crop plants.

Further research into water utilization in relation to soil held at a constant level of water saturation would also be useful. This would be valuable information to 1 ) identify optimal soil saturation conditions, 2) identify the level of soil 
saturation necessary for significant drought stress, 3) assess differences in water utilization with respect to soil saturation as a function of a line curve derived from experimental data, and 4) to assess the differences between strains of Arabidopsis with respect to wild type (Columbia) along this curve. 
Mutant Drought Phenotype Investigation 17

\section{$\underline{\text { References }}$}

Boyer, J. S. (1982). Plant productivity and environment. Science, 218(4571), 443448. doi: $10.1126 /$ science.218.4571.443

Crowell, D. N., \& Huizinga, D. H. (2009). Protein isoprenylation: the fat of the matter. Trends Plant Sci, 14(3), 163-170. doi: 10.1016/j.tplants.2008.12.001

Cutler, S., Ghassemian, M., Bonetta, D., Cooney, S., \& McCourt, P. (1996). A protein farnesyl transferase involved in abscisic acid signal transduction in Arabidopsis. Science, 273(5279), 1239-1241.

Fitzpatrick, A. H., Bhandari, J., \& Crowell, D. N. (2011). Farnesol kinase is involved in farnesol metabolism, ABA signaling and flower development in Arabidopsis. Plant J, 66(6), 1078-1088. doi: 10.1111/j.1365-313X.2011.04572.x

Gamboa, M. C., Baltierra, F., Leon, G., \& Krauskopf, E. (2013). Drought and salt tolerance enhancement of transgenic Arabidopsis by overexpression of the vacuolar pyrophosphatase 1 (EVP1) gene from Eucalyptus globulus. Plant Physiol Biochem, 73C, 99-105. doi: 10.1016/j.plaphy.2013.09.005

Ghabooli, M., Khatabi, B., Ahmadi, F. S., Sepehri, M., Mirzaei, M., Amirkhani, A., ... Salekdeh, G. H. (2013). Proteomics study reveals the molecular mechanisms underlying water stress tolerance induced by Piriformospora indica in barley. J Proteomics, 94C, 289-301. doi: 10.1016/j.jprot.2013.09.017

Hemmerlin, A., \& Bach, T. J. (2000). Farnesol-induced cell death and stimulation of 3-hydroxy-3-methylglutaryl-coenzyme A reductase activity in tobacco cv bright yellow-2 cells. Plant Physiol, 123(4), 1257-1268.

Hemmerlin, A., Reents, R., Mutterer, J., Feldtrauer, J. F., Waldmann, H., \& Bach, T. J. (2006). Monitoring farnesol-induced toxicity in tobacco BY-2 cells with a fluorescent analog. Arch Biochem Biophys, 448(1-2), 93-103. doi: 10.1016/j.abb.2005.10.017

Kumar, T., Uzma, Khan, M. R., Abbas, Z., \& Ali, G. M. (2013). Genetic Improvement of Sugarcane for Drought and Salinity Stress Tolerance Using Arabidopsis Vacuolar Pyrophosphatase (AVP1) Gene. Mol Biotechnol. doi: 10.1007/s12033-013-9695-z

Maurer-Stroh, S., Washietl, S., \& Eisenhaber, F. (2003). Protein prenyltransferases: anchor size, pseudogenes and parasites. Biol Chem, 384(7), 977-989. doi: 10.1515/BC.2003.110

Pei, Z. M., Ghassemian, M., Kwak, C. M., McCourt, P., \& Schroeder, J. I. (1998). Role of farnesyltransferase in ABA regulation of guard cell anion channels and plant water loss. Science, 282(5387), 287-290.

Running, M. P., Lavy, M., Sternberg, H., Galichet, A., Gruissem, W., Hake, S., ... Yalovsky, S. (2004). Enlarged meristems and delayed growth in plp mutants result from lack of CaaX prenyltransferases. Proc Natl Acad Sci U S A, 101(20), 7815-7820. doi: 10.1073/pnas.0402385101

Ubaidillah, M., Kim, K. A., Kim, Y. H., Lee, I. J., Yun, B. W., Kim, D. H., ... Kim, K. M. (2013). Identification of a drought-induced rice gene, OsSAP, that suppresses Bax-induced cell death in yeast. Mol Biol Rep, 40(11), 6113-6121. doi: 10.1007/s11033-013-2723-z 
Yalovsky, S., Rodr Guez-Concepcion, M., \& Gruissem, W. (1999). Lipid modifications of proteins - slipping in and out of membranes. Trends Plant Sci, 4(11), 439445.

Zhang, F. L., \& Casey, P. J. (1996). Protein prenylation: molecular mechanisms and functional consequences. Annu Rev Biochem, 65, 241-269. doi: 10.1146/annurev.bi.65.070196.001325 


\section{Supplemental Images}

\section{Image 1 - Wild type (Columbia) flats}

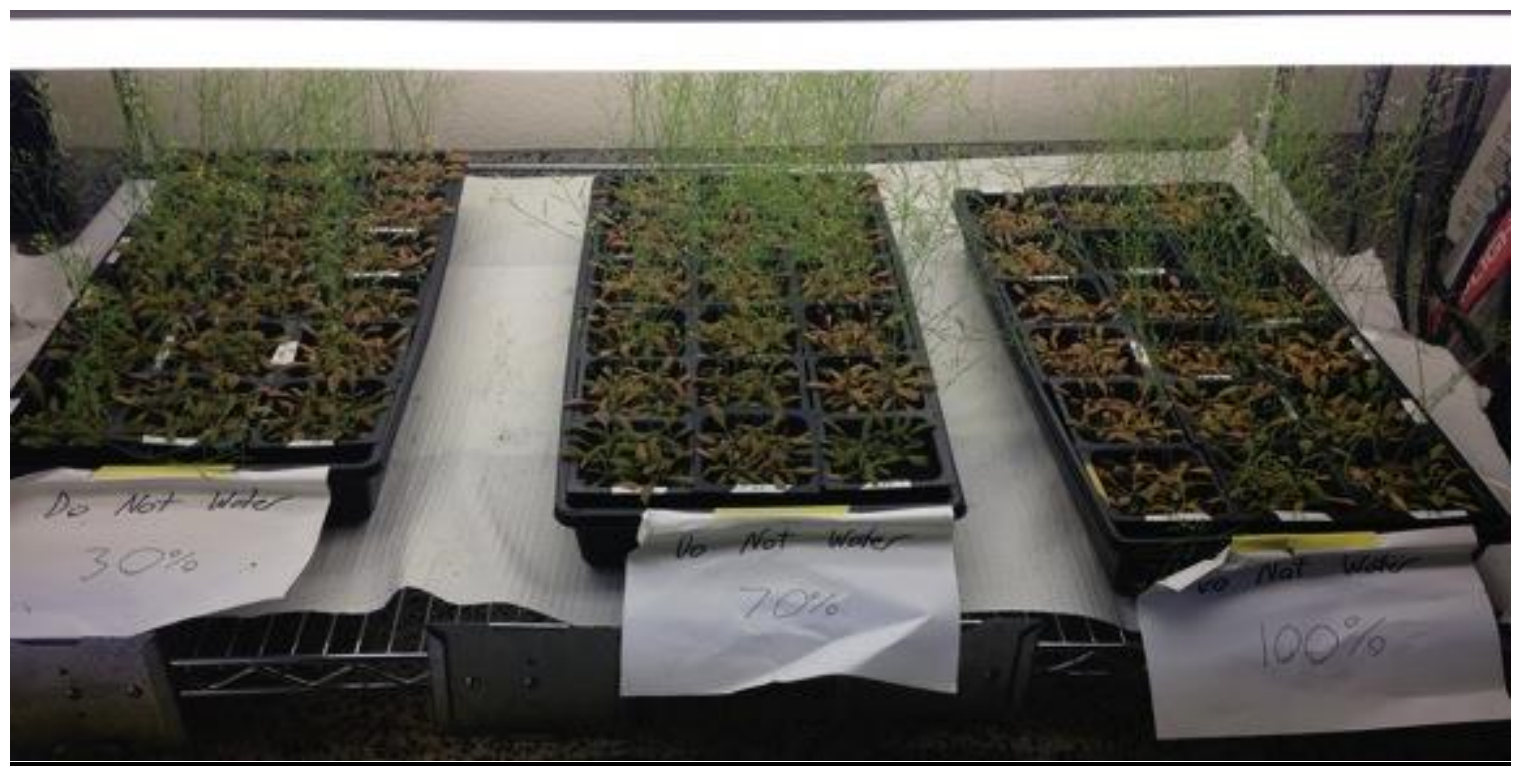

Image 2 - Ppal flats

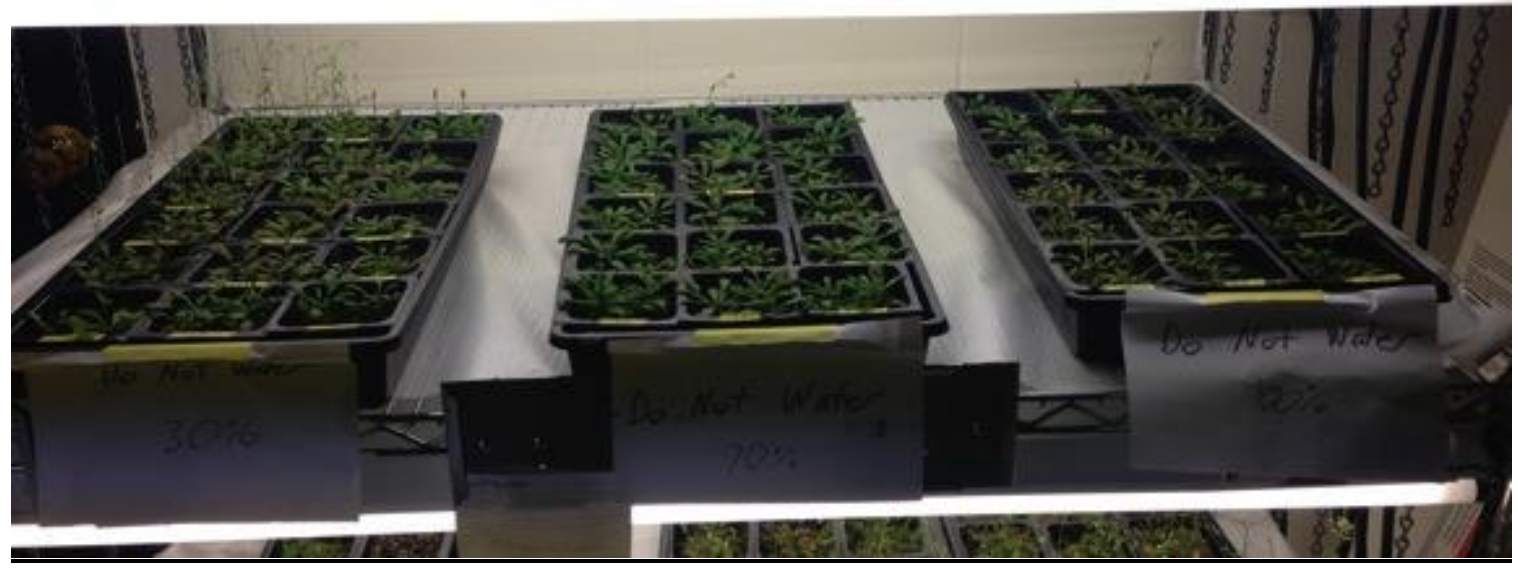




\section{Image 3 - Plp flats}

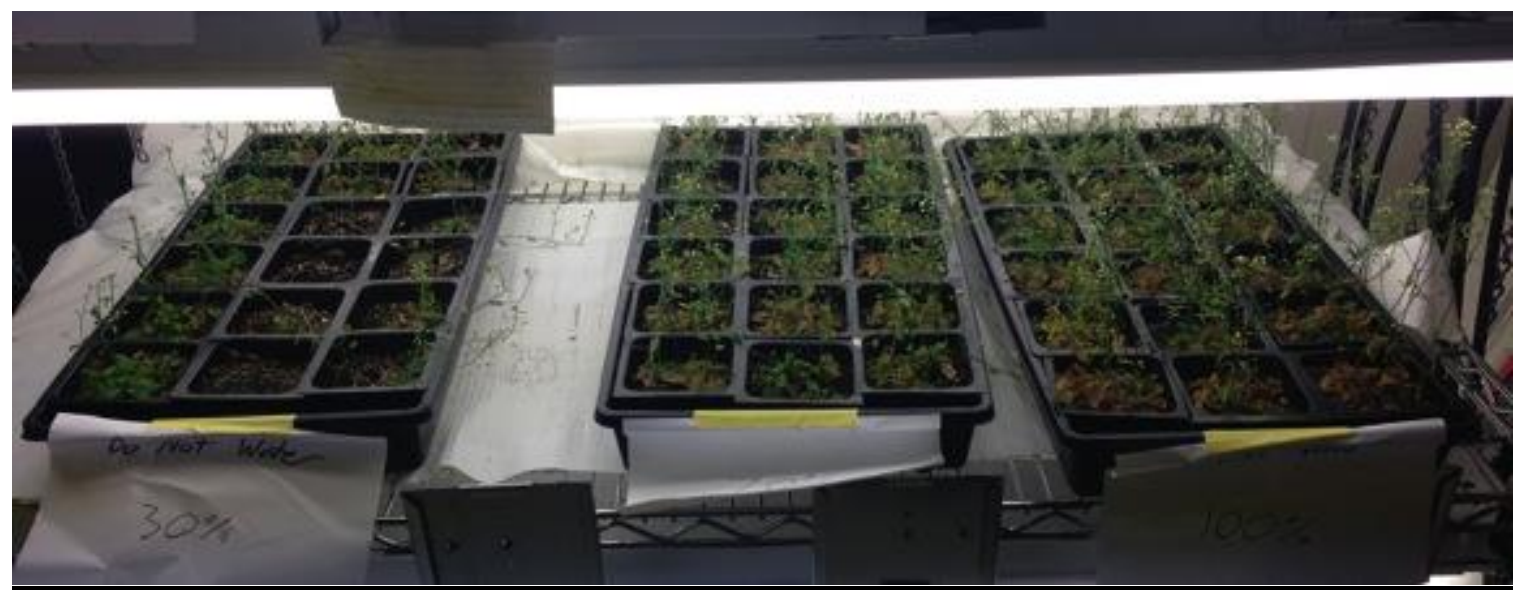

Image 4 - Wild type (Columbia) 30\% water saturation condition

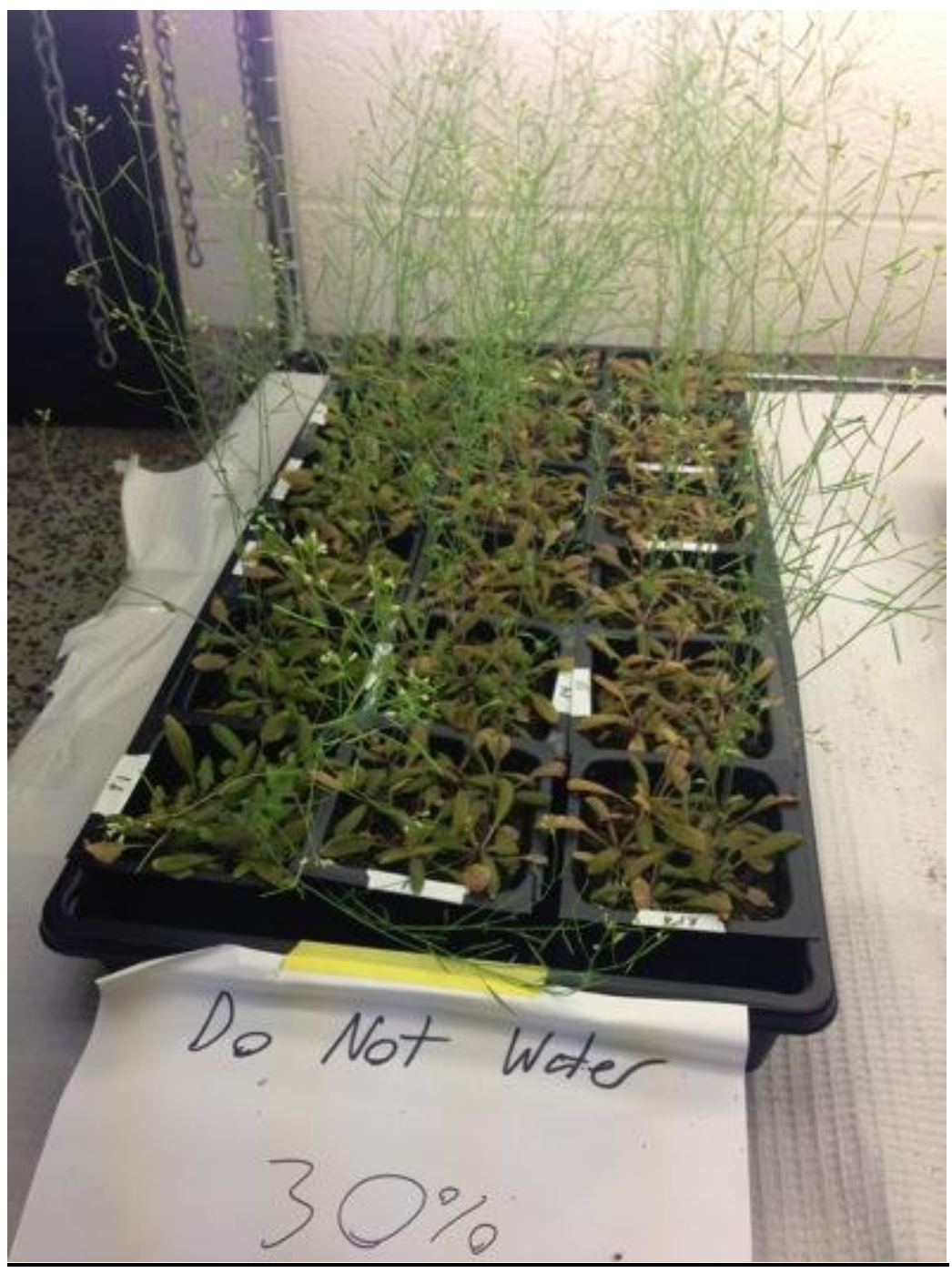


Image 5 - Wild type (Columbia) 70\% water saturation condition

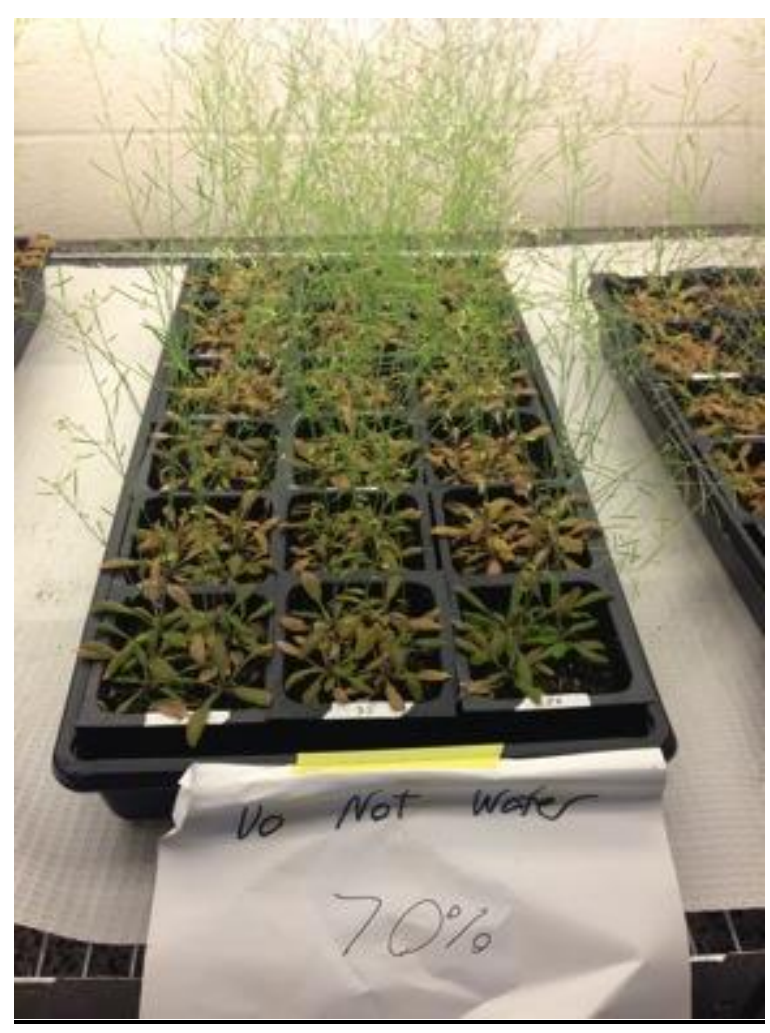

Image 6 - Wild type (Columbia) 100\% water saturation condition

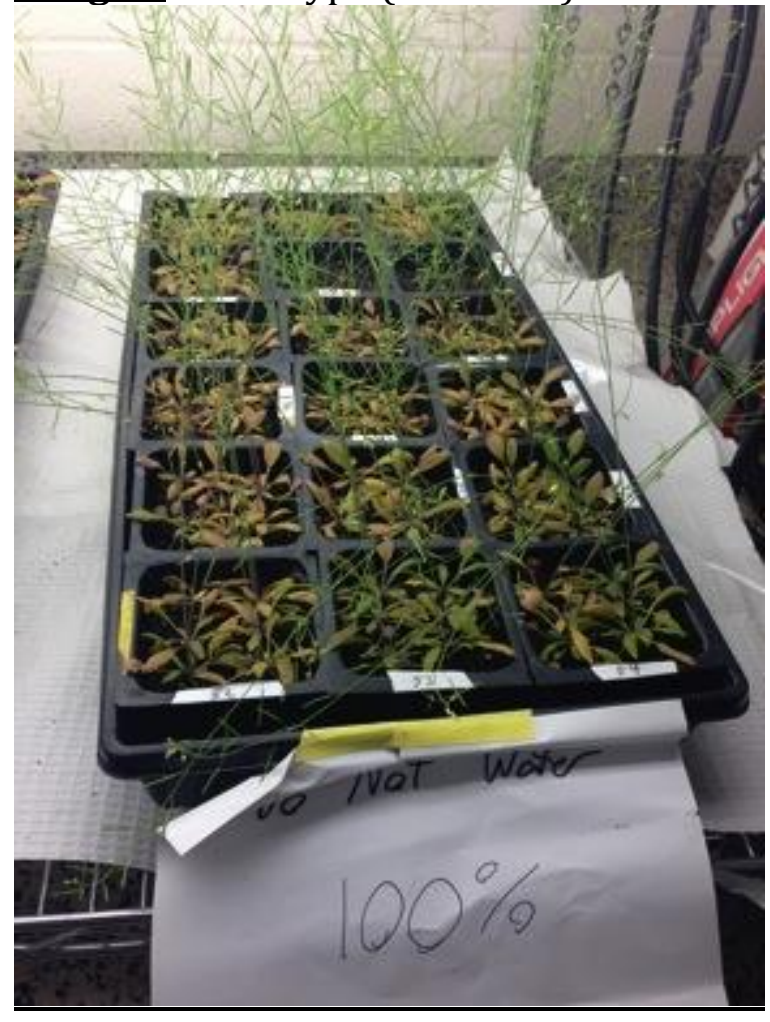


Image 7 - Ppal 30\% water saturation condition

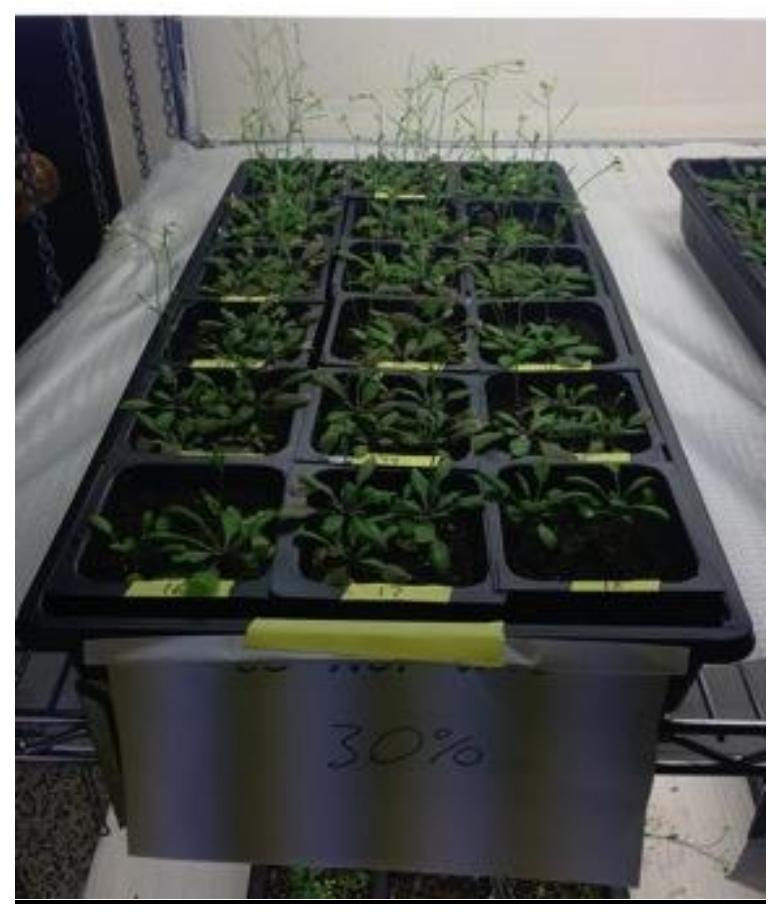

Image 8 - Ppal 70\% water saturation condition

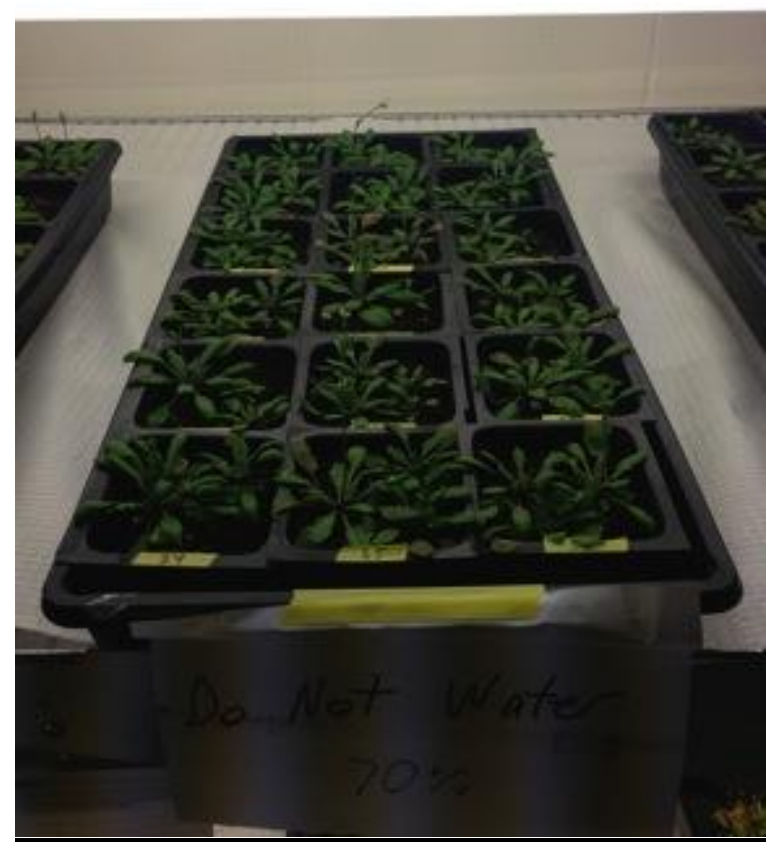


Image 9 - Ppal 100\% water saturation condition

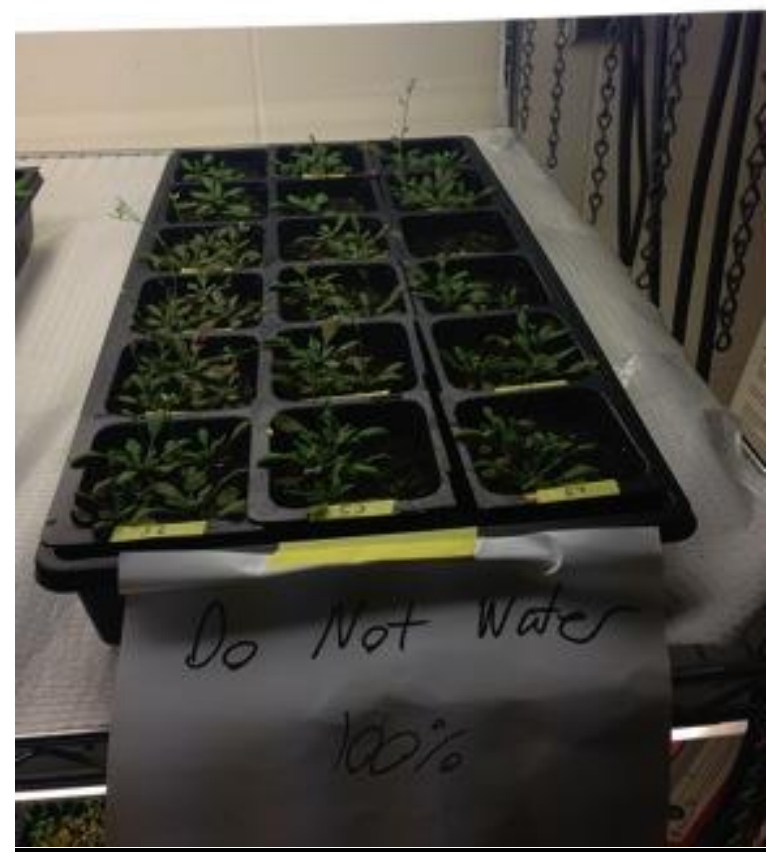

Image 10 - Plp 30\% water saturation condition

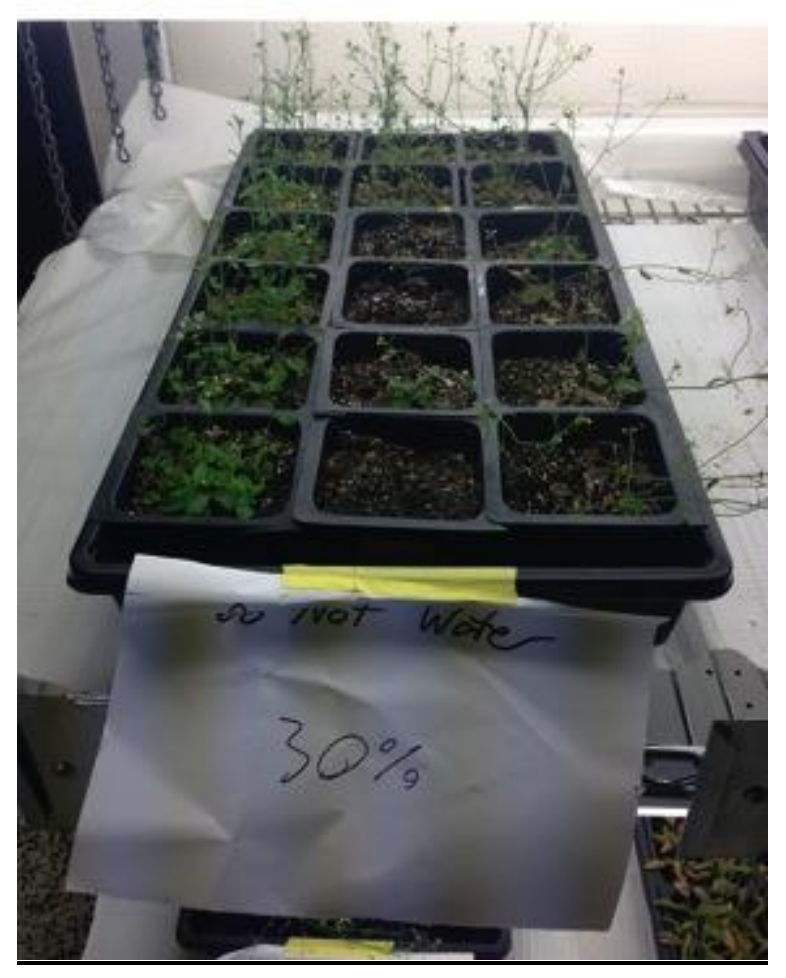


Image 11 - Plp 70\% water saturation condition

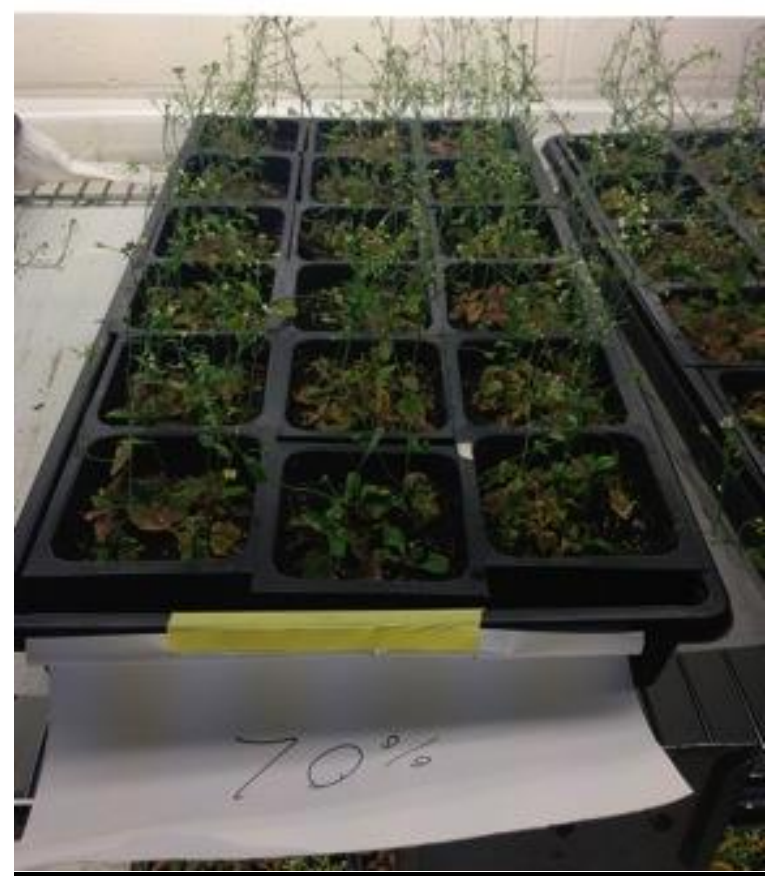

Image 12 - Plp 100\% water saturation condition

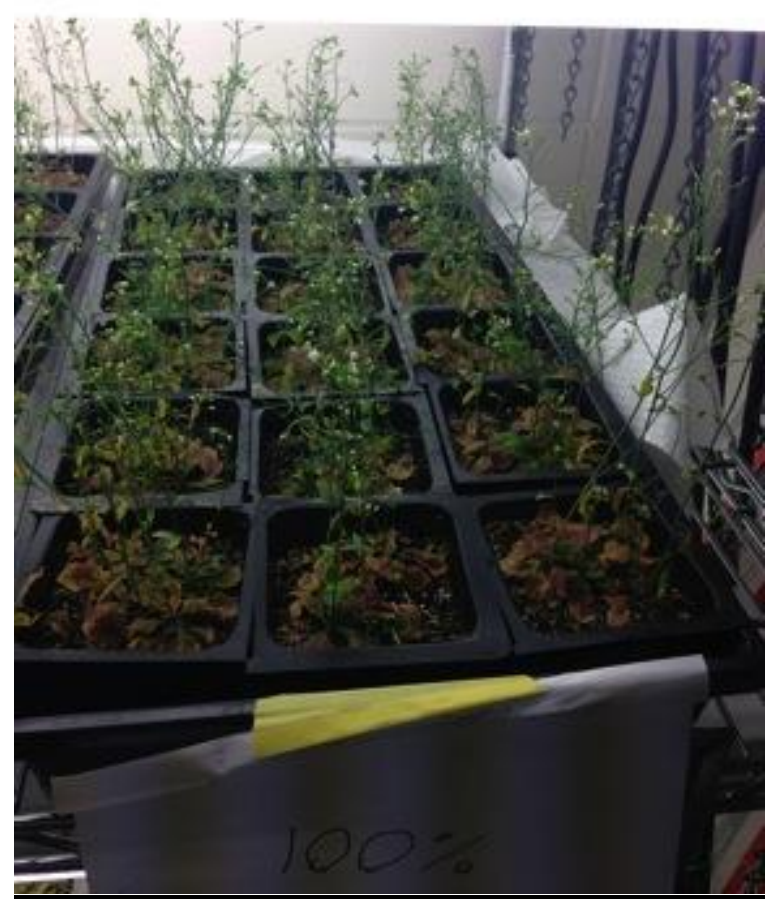


Image 13 - Growth Chamber flat with dome cover (From separate experiment)

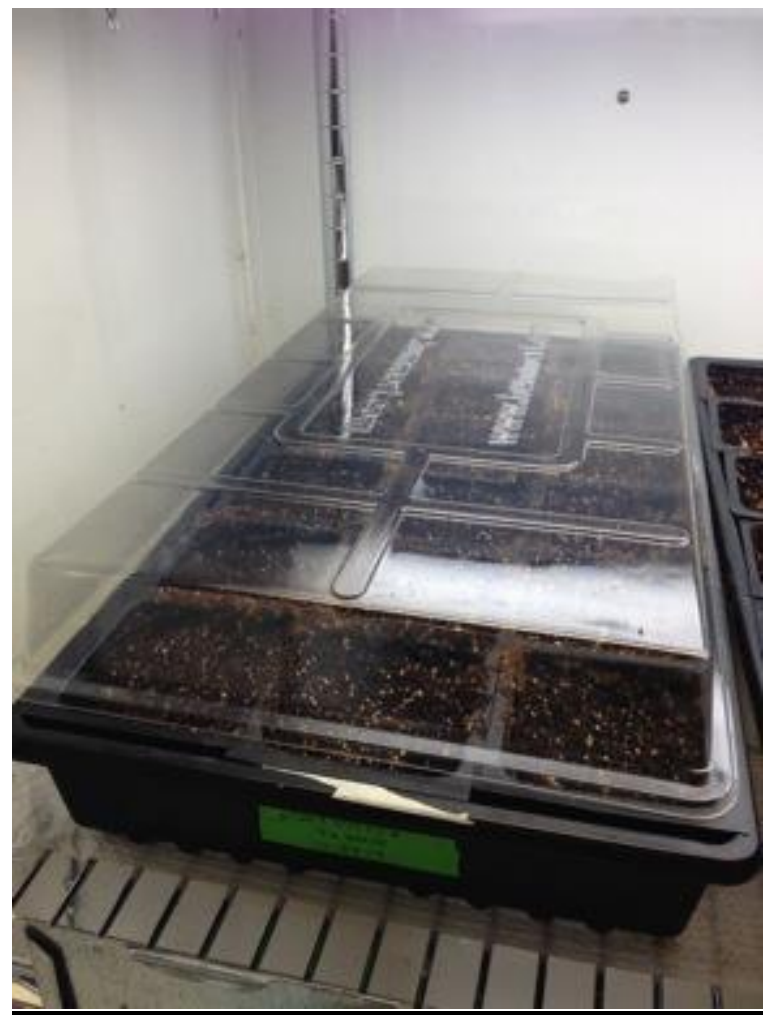

Image 14 - Point when covers are removed (From separate experiment)

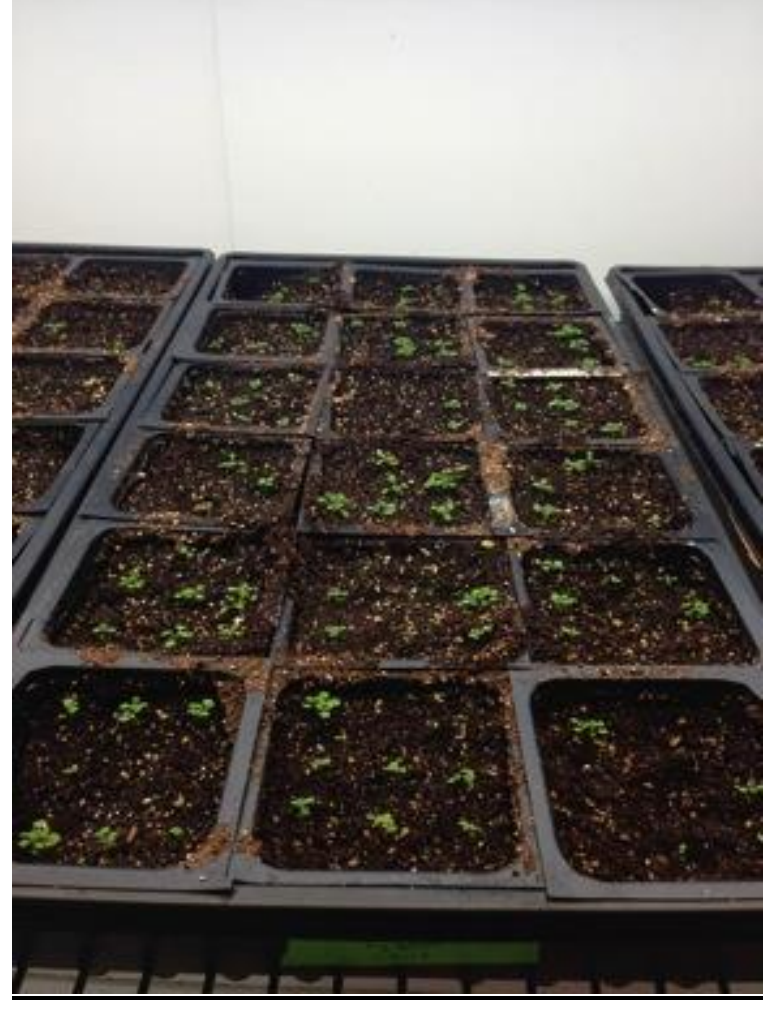


Image 15 - Point are which plants are deceased (From separate experiment)

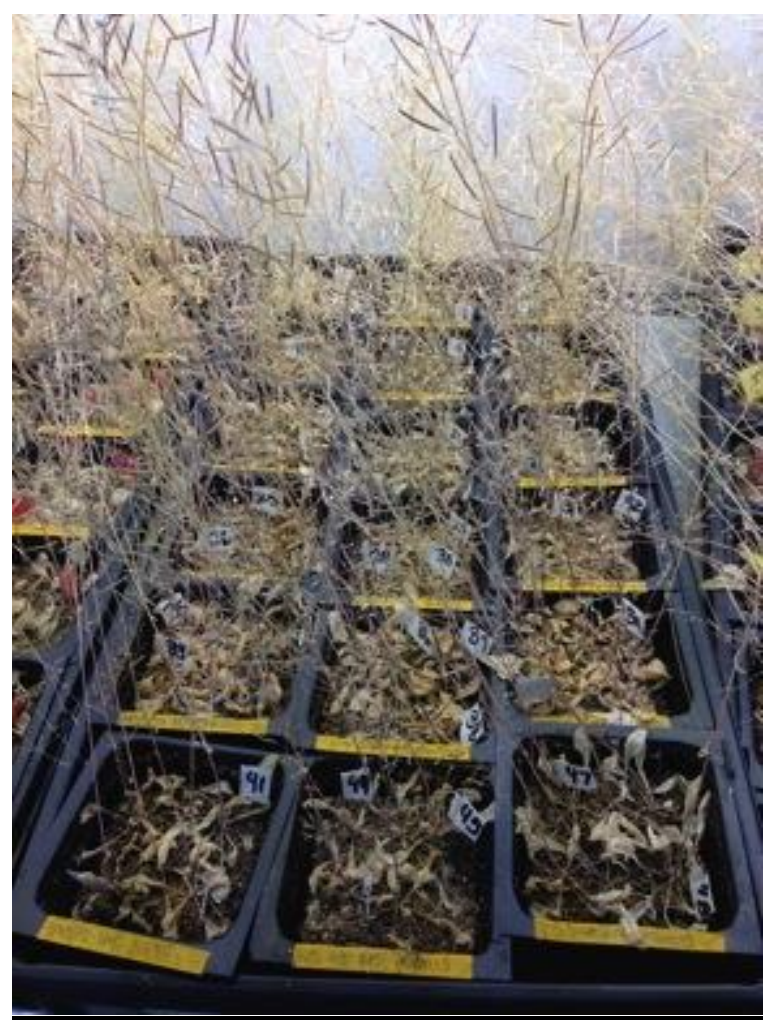




\section{Supplemental Figures}

Figure 1 - Experimental data table

\begin{tabular}{cc}
\multicolumn{2}{c}{ Columbia } \\
Water Utilization/Plant \\
$30 \%$ & 3.09 \\
$70 \%$ & 2.16 \\
$100 \%$ & 1.63
\end{tabular}

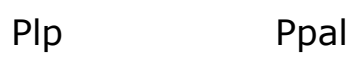

Base Evaporation
16.6
16.4
12.5

Average Seed Yield/Plant

$\begin{array}{rrrr}30 \% & 0.02305 & 0.01668 & 0.00634 \\ 70 \% & 0.03071 & 0.02125 & 0.00851 \\ 100 \% & 0.02695 & 0.01856 & 0.00915\end{array}$

Average BioMass/Plant

$\begin{array}{rrrr}30 \% & 0.04214 & 0.04364 & 0.03965 \\ 70 \% & 0.04787 & 0.05936 & 0.04616 \\ 100 \% & 0.04389 & 0.03335 & 0.06147\end{array}$

Average Plants/Pot

$\begin{array}{rrrr}30 \% & 5.9444 & 3.6667 & 4.6667 \\ 70 \% & 5.7222 & 3.5000 & 6.3889 \\ 100 \% & 5.7500 & 3.3529 & 6.0556\end{array}$


Figure 2 - Water utilization graph

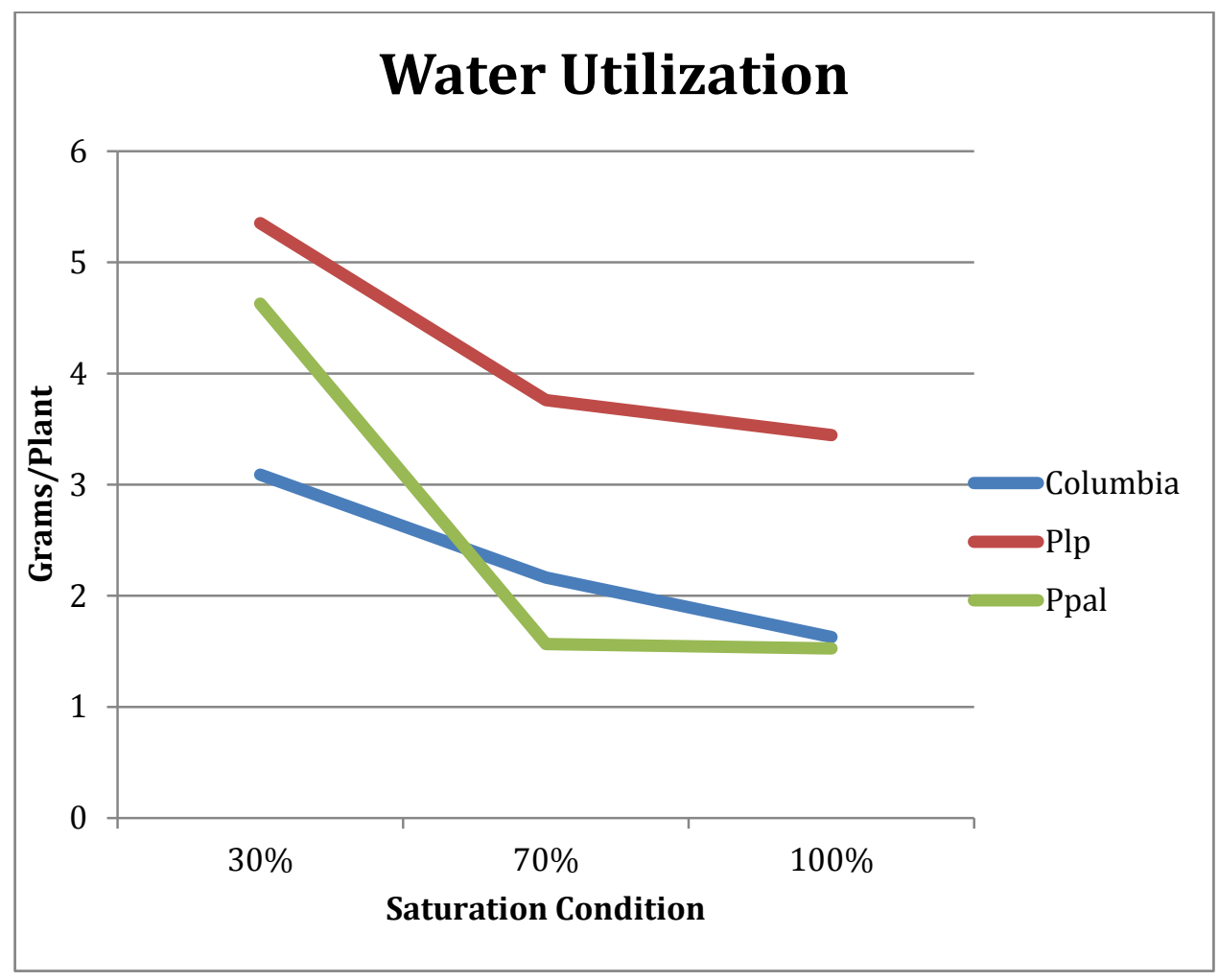

Figure 3 - Seed yield graph

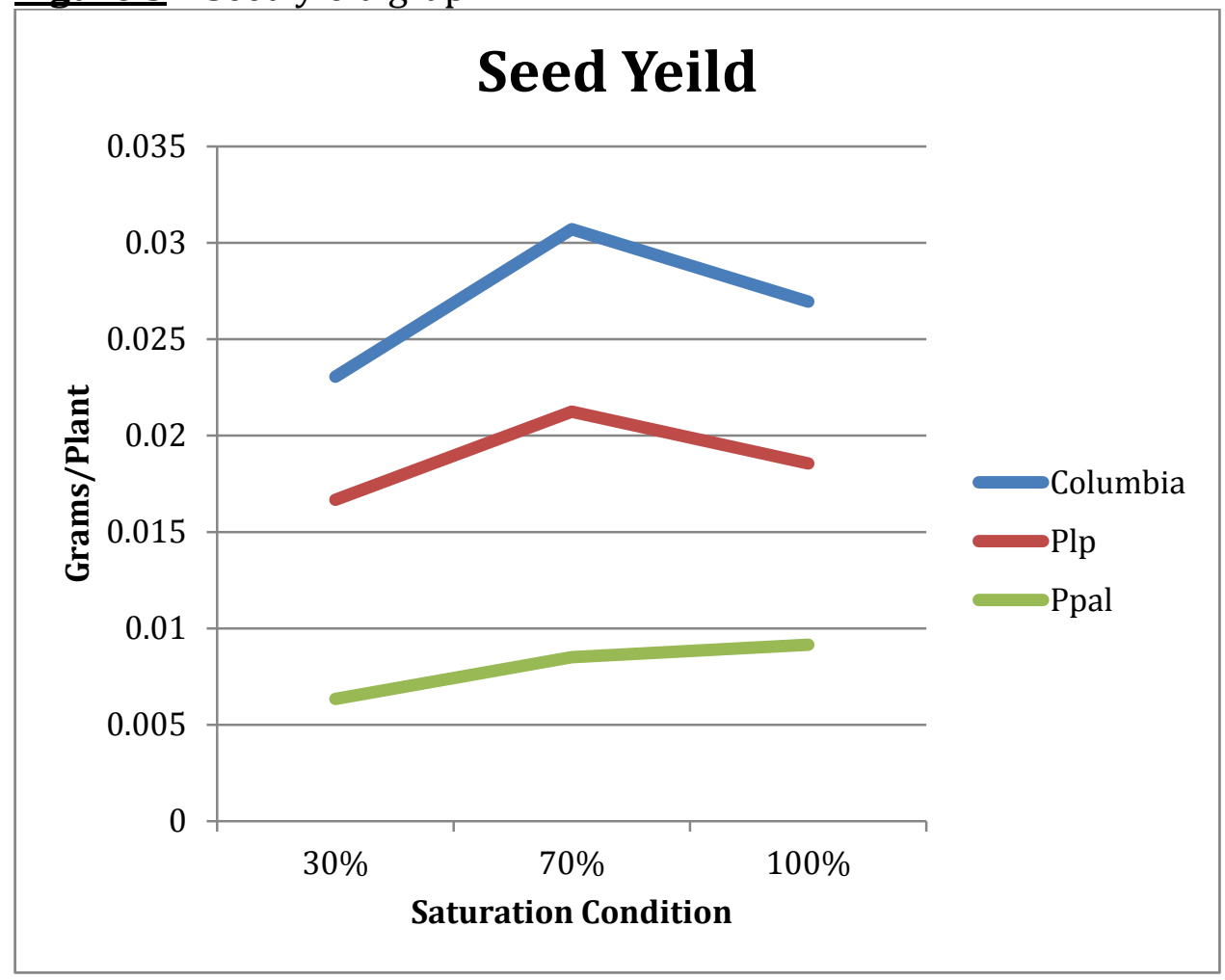


Figure 4 - BioMass graph

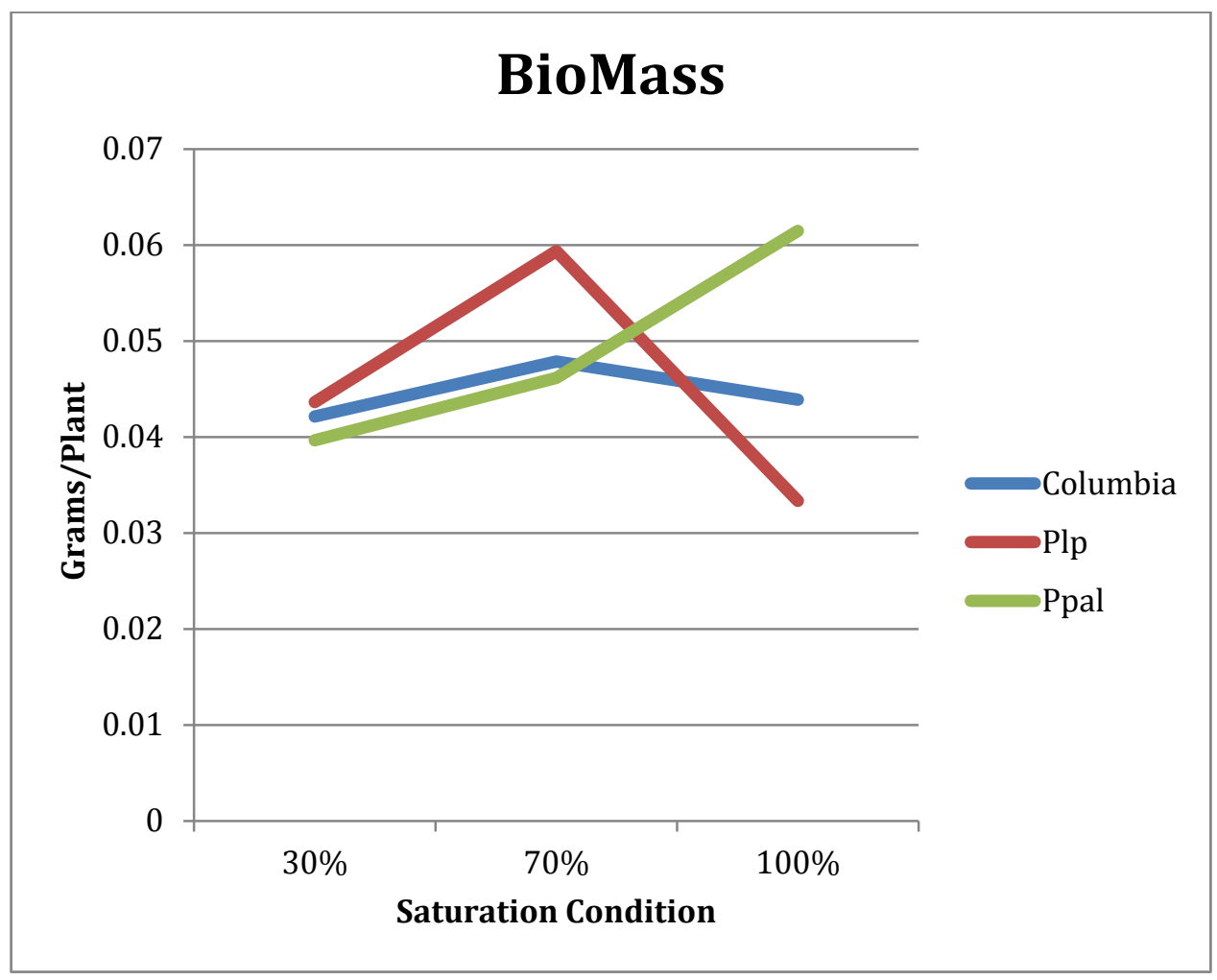

